\title{
REPRESENTAÇÕES DO AMOR EM LAIS DOS BRETÕES E LAIS DE MARIA DE FRANÇA
}

\author{
REPRESENTATIONS OF LOVE IN BRETON LAIS AND LAIS DE \\ MARIE DE FRANCE
}

\author{
Rosiane XYPAS
}

\begin{abstract}
Resumo: O amor é uma temática essencial na Idade Média literária francesa tendo o gênero lai como um dos principais gêneros em forma de verso curto rimado ou narrado. Buscamos neste artigo investigar as representações do amor feminino na Idade Média retratados em vinte e três lais encontrados nas obras Lais dos Bretões (2013) e Lais de Maria de França (2001) e compreender se tais representações sugerem algum modo de viver e de amar em nossa sociedade contemporânea. Para tal, apoiamo-nos nos sistemas de Objetificação e Ancoragem, de Jodelet (1984), oriundos da Sociologia e do conceito de Amor-Paixão, de Rougemont (1988), escritor e teórico cultural. Perguntamos em que medida essas representações influenciaram nosso imaginário ocidental acerca dos relacionamentos amorosos e proporcionaram, ao longo de gerações de leitores, estereótipos sobre a cultura francesa existentes até os dias atuais. Resulta que diversas representações dos lais analisados suscitam diversos déjà vu em nossa sociedade atual sobre o tema em questão. As representações do amor são construídas com espaços geográficos, em uma Bretanha Francesa, outra Inglesa, e em espaços não definidos. O perfil das mulheres é apresentado por um campo lexical positivo e as relações amorosas suscitadas nos lais analisados são punições amorosas da época.
\end{abstract}

Palavras-chave: Amor Feminino. FLE. Lai. Literatura Medieval. Representações.

Abstract: Love is an essential theme in Middle Age French literature being the genre lai one of the main ones in the form of a short rhymed or narrated verse. This paper seeks to investigate the representations of female love in the Middle Ages portrayed in twenty-three lais found in the works Breton Lais (2013) and Lais de Marie de France (2001) and understand if such representations suggest some way of living and loving in our contemporary society. Jodelet's Objectification and Anchoring systems (1984), from Sociology, and the concept of Love-Passion (1988), by the cultural writer and theorist Rougemont, are used as support for the analyses. The paper questions the extension these representations have influenced our Western imagination about love relationships and provided, for generations of readers, stereotypes about French culture that exist to the present day. It turns out that different representations of the analyzed lais give rise to several déjà $v u$ in our current society on the subject in question. The representations of love are built with geographical spaces, in a French and English Britains as well as in non-defined spaces. The profile of women is presented by a positive lexical field and the love relationships aroused in the analyzed lais are love punishments of the time.

Keywords: Female Love. FLE. Lai. Medieval Literature. Representations.

\section{Introdução}

No âmbito universitário, os estudos literários franceses abrangem clássicos da literatura da Idade Média à contemporânea, geralmente representados por autores ditos mais

\footnotetext{
* Doutorado em Letras - Université de Nantes/UFPB. Professora da Universidade Federal de Pernambuco. E-mail : rosiane.mariasilva@ufpe.br
} 
significativos. No tocante à literatura francesa da Idade Média, ela é representada por obras escritas desde o século XII indo até os fins do século XV, o que equivale a uns quatrocentos anos de escritos franceses que se misturam tanto com a história da França quanto com a reflexão sobre o que é Literatura nesse período. Conforme Cerquiglini-Toulet (2007), esse período foi marcado por um bilinguismo latim-francês, e, nele, faz-se a distinção de duas culturas: uma sábia, atrelada às pessoas que dominavam o latim, como o clero, e a dos laicos, que reunia os não-letrados, como a plebe e uma grande parte da classe nobre francesa.

$\mathrm{Na}$ Idade Média francesa, pontos relevantes, como a presença das línguas oc e oil, como também de seus dialetos, o nascimento dessa Literatura, como as noções de gêneros literários e sua escrita atrelada à invenção da tipografia, compõem o panorama dessa extensa literatura medieval. Dos estudos literários em Francês Língua Estrangeira (doravante, FLE), domínio pelo qual pensamos a Idade Média neste artigo, ouvimos de vários estudantes, que tal período é temido por eles, porque consideram as obras bastante rebuscadas no tocante ao vocabulário. Assim, pensamos que para uma introdução aos estudos literários no medievo francês, uma investigação sobre as representações sociais da temática do amor da mulher pelo gênero lai pudesse diminuir a apreensão dos estudantes.

Ressaltamos que os lais são poesias predominantemente da Idade Média. O lai é um poema narrativo ou lírico curto de origem celta. Este gênero participa da literatura de cortesia e pode ser cantado, acompanhado com uma harpa. Amon e Bomati (2002, p. 258, tradução minha) ${ }^{1}$ afirmam que os lais "narram uma aventura amorosa em um reino mágico". O lai, surgido na baixa Idade Média, é uma variedade literária que suscita divergências etimológicas e textuais entre críticos literários, historiadores e pesquisadores. Constatamos, em nossos estudos, que a palavra "lai" está relacionada com a musicalidade poética e divide-se entre o lai lírico, poema-canção de doze estrofes heterométricas de versos curtos e de temática melancólica, e o lai narrativo, baseado nas fábulas bretãs e nas lendas arturianas, cuja estrutura textual assemelha-se ao conto. Tais lais narrativos utilizam-se de elementos mitológicos e culturais celtas da Bretanha Insular (atual Inglaterra) e da Bretanha Armórica (atual noroeste da França), denominados de Matéria da Bretanha.

As representações do amor da mulher da Idade Média foram estudadas em um corpus composto com duas obras: Os Lais dos Bretões (2013), considerados como lais narrativos, e Lais de Maria de França (2001), os quais introduzem na literatura o conceito do Amor Cortês. Ressaltamos que o estudo das duas obras conjuntamente faz-se necessário visto que tais

\footnotetext{
${ }^{1}$ No original: "Ces æuvres racontent une aventure amoureuse imprégnée de féerie." 
aventuras amorosas eram narradas oralmente pelos bretões, posteriormente transformadas em lais pelos trovadores, que, por sua vez, foram reapropriados e popularizados pela escritora Maria de França.

No primeiro momento, a fim de apreender as representações do tema em questão, foram analisados vinte e três lais, unindo as duas obras, ou seja, onze nos Lais dos Bretões (2013) e doze nos Lais de Maria de França (2001). No segundo, fizemos um levantamento quantiqualitativo no tocante aos espaços geográficos, distinção entre as personagens femininas, sentimentos/qualidades e enamoramentos, com o intuito de analisar para demonstrar semelhanças e diferenças entre as obras literárias em questão.

Marie de France (1154-1189) foi a primeira mulher escritora na Idade Média. Essa voz “menor” em meio a vários escritores se destaca, pois, segundo Amon e Bomati (2002, p. 337, tradução minha) $)^{2}$, ela "é essencialmente conhecida por ter dado uma versão francesa aos lais bretões".

Ora, a análise dos lais, plenos de aventuras amorosas em um reino mágico, não pode ser feita sem a compreensão das representações. Por isso, ressaltamos que as representações sociais de uma língua e de uma cultura são baseadas em uma ancoragem transmitida de geração a geração, notadamente pelo grupo social ao qual pertencemos. Os estudantes, por exemplo, chegam à universidade com suas representações sociais da língua francesa, e, para eles, a língua é bela, chique, emocionante, rica, diferente, motivadora, um campo lexical rico em qualidades positivas. Notadamente, as representações sociais são fundadas com objetivações de senso comum sobre a França e os Franceses. E o que se fala da literatura francesa é, por muito, nestas representações.

No ano de 2017, na disciplina de Literatura Francesa da Idade Média, algo nos chamou a atenção. Por um lado, observamos que o lai é um gênero muito pouco conhecido dos estudantes, e ele fora recebido com estranhamento por eles. Indubitavelmente, em uma época em que nós brasileiros nem tínhamos sido achados, a França já produzia textos literários que representavam, já naquela época, seus modos e costumes de vida social, e a temática do amor da mulher era relevante na sociedade feudal. Por outro lado, a necessidade investigativa se dá pelo fato de que o lai está muito pouco presente em livros didáticos de língua e de literatura francesas para o FLE. Nossa premissa é que, pelo lai, o estudante poderá ampliar suas imagens de referência e as imaginantes sobre a sociedade francesa da época, as da mulher da Idade Média, através da

\footnotetext{
${ }^{2}$ No original: "Marie de France est essentiellement connue pour avoir donné une version française des lais bretons."
}

Revista Graphos, vol. 22, n³ 3, 2020 | UFPB/PPGL | ISSN 1516-1536 
voz feminina de Marie de France, que não trata apenas do amor feminino em sua obra.

O objetivo deste artigo é de compreender as representações do amor medievo. Estaria ele presente em nossa sociedade hoje em dia?

As teorias literárias estudadas foram sobre o gênero lai e sobre o amor cortês nele representado, tendo em mente, segundo J. Froissart apud Cerquiglini-Toulet (2007, p. 123, tradução minha) $)^{3}$, que "o amor é a grande matéria em toda Idade Média”. O amor é canto e agrada. Os teóricos sobre a Idade Média convêm em seu conceito de Literatura que ela existe porque existe autor, matéria a ser tratada e um público que a lê. Em nossos dias, concebemos que a Literatura, além de retratar e eternizar a cultura de uma época, dá conta de diversos termos-chave que a compõem, tais como autor, texto, leitor, divulgação, adaptação, entre outros.

O procedimento metodológico qualitativo adotado neste artigo, apresenta estudos de termos-chave como representações, idade média e amor. Embora sejam apresentados de modo breve, esperamos claros o suficiente para atingir nossos objetivos. Em seguida, gráficos foram elaborados, pelos quais comentamos brevemente os espaços amorosos dos deslocamentos dessas mulheres e seus perfis contidos nos lais lidos. Enfim, a partir das teorias sobre os sistemas de Objetificação e Ancoragem apontados por Jodelet (1984), buscamos, na sociologia, compreender o valor acordado ao termo-chave "representação", e, em se tratando do conceito de Amor-paixão, apoiamo-nos em Rougemont (1988).

\section{Breve panorama da Idade Média literária Francesa}

Segundo Cerquiglini-Toulet (2007), questões fundamentais como o conceito de Literatura, o bilinguismo latim-francês, a definição da língua oc e oil e seus dialetos, os gêneros literários, a questão da fala, da escrita na Idade Média, a questão do autor, da composição, do público feminino da época, da ficção do autor, da ordem da escrita, do título da obra, da igreja, da universalidade, das províncias literárias, dos temas do amor, do sonho, de Deus, de sua forma, do verso, da rima e da razão, dentre outros, são fios condutores que compõem as representações da literatura francesa da Idade Média. Esta se confunde com as origens da Literatura escrita em língua francesa. Um francês arcaico apenas lido por especialistas. No entanto, as obras literárias que compõem estes 400 anos, hoje, já são estudadas também por um francês moderno, tanto no francês língua materna (FLM) quanto no francês língua estrangeira (FLE).

3 No original: "L'amour est la grande matière en tout le Moyen Âge."

Revista Graphos, vol. 22, n 3, 2020 | UFPB/PPGL | ISSN 1516-1536 
É com Cerquiglini-Toulet (2007) que discorremos brevemente sobre a Idade Média literária francesa. Tudo começa por necessidade de compreender as origens: da canção de gesto, pode-se dizer que nasce nas lendas ligadas à igreja em rotas de peregrinagem. No começo, era o poeta na afirmação de uma criação individual de textos, mas outros dizem que no começo era a voz. As origens da Literatura na Idade Média fazem-se tríade: Igreja, criação e voz. Afirmamos com Cerquiglini-Toulet (2007) que, no começo, era o francês uma língua jovem, uma língua nova. As obras oriundas desse bilinguismo latim-francês eram lidas pelos sábios, o clero, e não pelos laicos, nem a nobreza. Eles contavam com suas memórias e, posteriormente, a escrita para os registros literários. Desse bilinguismo, amplia-se o entendimento para a existência das línguas ditas oc, língua do sul, e a oïl, a do norte, como também outras línguas e dialetos. Assim, teremos uma grande riqueza de línguas, pois havia línguas

não oriundas do latim [que] se encontram no território francês daquilo que vai se tornar França: flamengo, bretão e esta diversidade [linguística] é pensada em termos de riqueza. [No entanto] o status dos dialetos é mais complexo, fazendo nascer sentimentos de superioridade e inferioridade. (CERQUIGLINI-TOULET, 2007, p. 35-36, tradução minha) ${ }^{4}$.

Ora, "minha língua é boa porque nasci na França” (CERQUIGLINI-TOULET, 2007, p. 35 , tradução minha $)^{5}$. De resto, sabemos que a fama da língua francesa falada em Paris e na região oeste da França, conhecida como Maine et Loire, é considerada como um bom francês. E essa representação atinge os interessados e estudiosos do FLE, notadamente nossos estudantes, que trazem consigo representações da língua francesa e a paixão pela literatura criada por esta língua.

Ao lado da busca das origens das línguas e suas diversidades, acrescentamos a matéria com a qual era feita a Literatura da Idade Média. Certo que é com as línguas, mas também com os dialetos, com os quais nascem as singularidades das matérias produzidas. Assim, a língua francesa seria "mais apta para a composição de versos, canções de amor e de poemas satíricos" (CERQUIGLINI-TOULET, 2007, p. 37, tradução minha $)^{6}$. Entenda-se que, aqui, se fala da língua $o c$, que tem um peso considerável na escrita sobre o amor e com a reputação dos provinciais franceses no domínio. No decorrer da leitura do capítulo sobre a Idade Média

\footnotetext{
${ }^{4}$ No original: "Des langues non issues du latin se rencontrent sur le territoire de ce qui deviendra la France : flamand, breton, et cette diversité est pensée en termes de richesse. (...) Le statut des dialectes est plus complexe faisant naître des sentiments de supériorité ou d'infériorité."

${ }^{5}$ No original: "Mon langage é bon car je suis né en France."

${ }^{6}$ No original: "La langue française est plus apte à la composition de vers, de chansons d'amour et de poèmes satiriques."
} 
literária francesa, entendemos que as línguas começam a desenvolver seus poderes umas sobre as outras. Nasce, então, o francês como uma língua cultural fora da França, ou seja, ela era utilizada fora do hexágono, escolhida pelos italianos na escrita de suas obras. A língua francesa vai, cada vez mais, ganhando prestígio pela sua doce pronúncia e por ser agradável a ouvir, dirão os próprios escritores italianos. A tal ponto que "nasce no norte da Itália, no século XIV, um dialeto literário, o franco-italiano. [...] escreve-se também em francês no reino latim do oriente, mesmo sendo italiano" (CERQUIGLINI-TOULET, 2007, p. 40, tradução minha) 7 . Embora saibamos que a língua francesa, tida como a língua da cultura até meados dos anos 70 do século passado, englobe os cinco continentes, apontamos que, desde o século XIV, a obra Frère de Joie et Soeur de Plaisir (Irmão de alegria e irmã de Prazer), de um autor anônimo, sugere em seu incipit que, "mesmo que os franceses tenham uma boa língua, não gosto nada da linhagem deles porque são orgulhosos e sem piedade, [...] é por isso que não quero falar francês" (CERQUIGLINI-TOULET, 2007, p. 41).

Em se tratando da escrita na Idade Média Francesa, é ainda com Cerquiglini-Toulet (2007) que lemos que, fora as qualidades intelectuais, o sentido e a memória de quem escreve, as ferramentas utilizadas eram a tinta, o papel, a escrivaninha, o pequeno canivete para se apagar os erros, a pluma e a vontade. Desenham-se, assim, assuntos do espírito e da matéria para o desenvolvimento das obras literárias da Idade Média. O público feminino recebia uma atenção especial na figura da ouvinte e da leitora. Nos romances, damas e grandes damas são bastante mencionadas. Há damas que compõem poesias, lais em reação a episódios maravilhosos acrescidos de valores do real, pois os lais agradam-na ordinariamente. O lugar específico da escuta desses textos era o quarto das damas. Normalmente, estas não liam o latim, e os textos literários que liam ou ouviam já estavam traduzidos em francês.

As obras tocam os meios, como a igreja com os cleros, que sabiam tanto o latim quanto o francês. Eles detinham o saber e eram responsáveis por sua difusão. Com a criação da universidade em 1200 e confirmada pelo Papa Innoncent III em 1215, houve uma estruturação de um meio leitoral que, por tradução, passa o saber teológico, filosófico, astronômico, medicinal, livros de Aristóteles, mas também técnicos, do latim ao francês. Ressaltamos igualmente as querelas entre Orleans e Paris, sendo Orleans aquela que lutava pela gramática e as obras clássicas, enquanto Paris, pela lógica e o estudo de Aristóteles; os cursos que contribuem com a difusão das obras; a cidade, desde o século XIII, pensada enquanto rede que

\footnotetext{
${ }^{7}$ No original: "Naît ainsi dans le nord de l'Italie au XIVe siècle un dialecte littéraire, le francoitalien [...] On écrit en français dans le royaume latin d'orient, même si l'on est italien."
} 
une prazeres e perigos, tavernas e fornos; a rede de amigos como em um sistema feudal ligando poetas com laços de amizades, mas também de rivalidade e jogo. Enfim, as províncias literárias que acolhem pensamentos diversos advindos da estratificação social e do pensamento dos territórios e regiões. A consciência literária passa por uma percepção de províncias literárias, como evocará o sintagma douce france advindo de canções de gestos, presentes em nosso imaginário até hoje.

No campo literário, as matérias são diversas: o cantar de gestos é um gênero importante da literatura medieval e se apresenta em três gestos: o gesto do rei; o gesto do doon, ou ciclo dos barões revoltados, e o gesto de Garin de Monglane, serviços prestados ao rei. O contar de Artur advém da Bretanha e é posto como signo da ficção e do divertimento sobre títulos das obras mais célebres, deformando-os, permutando os termos; d'Amours (dos amores), como a grande matéria da Idade Média, porque se atém ao poeta pelo canto ao amor, e a outra se atém ao público, porque ele o aceita e nele se compraz. E, por fim, a matéria é Deus, que advém pelos autores chamados moralistas, que escolhiam o que se devia ler. Esta era uma matéria inesgotável para todos eles. Em se tratando das vozes da escrita, temos o belo, o agradável e a consciência das formas, tais como o verso e a prosa, a rima e a razão, modelos das estrofes e a utilização delas, o nascimento de um pensamento social das formas e o imaginário da escrita. Mas a evolução da literatura na Idade Média suscita a construção do sentido, pensa-se no símbolo e no signo, na disjunção e na não-disjunção, em poderes ambíguos, o sonho, a metamorfose, a alegoria e os jogos visuais. A literatura medieval se oferece a nós como um enigma.

Enfim, para que esse breve panorama faça sentido nos estudos da temática proposta, precisamos compreender os sintagmas representações sociais, amor paixão e amor cortês.

\section{Compreendendo os sintagmas representações sociais, o amor-paixão e amor cortês}

O rápido passeio que fizemos pela Idade Média francesa literária pode entrar em concordância com a teoria das representações sociais de Jodelet (1984), unindo representações sociais e amor cortês? De acordo com a psicóloga social, a humanidade é concebida por sujeitos sociais que, na idade adulta, se inscrevem em situações sociais e culturais definidas. Enquanto sociedade, essas situações são preenchidas por "valores, tradições e normas" (JODELET, 1984, p. 27), que reproduzimos diariamente em nosso cotidiano, formando um pensamento social aceito pelas comunidades nas quais vivemos. Partindo do pressuposto de que toda representação social é uma visão coletiva e/ou individual que temos sobre alguém ou sobre algo, a autora 
propõe dois sistemas de formação de representações, desenvolvidos pelo psicólogo social Serge Moscovici nos anos 1980: os sistemas de Objetificação e Ancoragem.

$\mathrm{Na}$ Objetificação, a representação social torna-se indissociável entre objeto e conceito, surgindo, dessa forma, o que chamamos de clichês, e as fórmulas que sintetizam uma imagem não-familiar em uma imagem distinta. Jodelet (1984) classifica a objetificação em três fases: 1 . A seleção e a descontextualização das informações sobre tal objeto; 2. A formação de uma estrutura imaginária, realizada no nível consciente e inconsciente; 3. A naturalização dessa imagem que permite que ela tome forma na sociedade. No sistema de Ancoragem, classificamos e estipulamos regras sociais a esse imaginário criado na objetificação. É nesse sistema que algo geral torna-se distinto. Através da Ancoragem, o Amor, visto como um sentimento natural, torna-se um objeto a ser reverenciado e alcançado pelos ideais difundidos na Objetificação.

Ainda de acordo com a autora, o mecanismo da ancoragem também possui fases distintas: a ancoragem de significação de sentido, na qual propomos uma hierarquia de valores para a imagem objetificada; a ancoragem como instrumentalização do saber, que permite compreender como os elementos da representação circulam na sociedade; a cristalização da ancoragem, que cria um sistema de orientação e de realidade da objetificação de algo ou alguém. Enfim, Jodelet (1984, p. 66) afirma que "as representações comportam sempre algo do social e tornam-se categorias da linguagem".

Essas categorias, segundo a autora, sempre representarão um objeto, sempre darão um caráter imaginário ao objeto, se tornarão um conceito simbólico, representativo, construtivo, autônomo e criativo, que regem a forma como conceituamos as ideias e classificamos tudo ao nosso redor, criando, assim, opiniões/morais cristalizadas socialmente. Desse modo, os sistemas de objetificação e ancoragem são suscitados nos lais estudados, uma vez que, na obra Os Lais dos Bretões (2013), mais antiga e oriunda das canções folclóricas, o amor era visto como um sentimento a ser conquistado e/ou merecido através de ações heroicas, ao mesmo tempo em que era tangível ao cavaleiro adentrar no mundo maravilhoso. Tais representações são vistas até hoje por intermédio, por exemplo, do gênero Conto de fadas. Entretanto, na obra Lais de Maria de França (2001), fortemente influenciada pela vida regrada da corte e pela religião, a representação do amor faz-se através da expiação e da redenção.

De acordo com Rosenfield (1992), a Idade Média foi um período marcado por contradições de aspectos político, religioso, artístico e social, que influenciaram a forma como concebemos alguns conceitos abstratos, dentre eles, o Amor, tema universal da literatura até os dias atuais. Em sua análise histórica, a autora observa que a literatura amorosa foi utilizada 
como uma arma sócio-política pela Nobreza e pela Igreja, que lutavam entre si pela dominação ideológica da sociedade: por um lado, o sensualismo pagão de Eros, por outro, a ternura espiritual cristã do Ágape.

Segundo Rosenfield (1992), na época carolíngia dos séculos IX e X, a união amorosa dava-se de duas maneiras distintas. Aos senhores de terras, soberanos, chefes de tribos ou primogênitos, o casamento era uma forma de contrato, no qual as famílias negociavam dinheiro (dote) e poder (hierarquia) através da união de seus herdeiros. Entretanto, aos demais filhos homens, excluídos dessa responsabilidade social e financeira, restavam as aventuras heroicas, a busca pela própria riqueza e a conquista informal das amantes, que incluía raptos, estupros e concubinagem. Para a autora, isso representava a dicotomia da "lógica da possessão" versus a “conquista selvagem” (ROSENFIELD, 1992, p. 22).

Ainda com Rosenfield (1992), a influência da Igreja nos séculos XI e XII, os antigos hábitos de mancebia e rompimento de contratos matrimoniais por infertilidade ou casamentos mais vantajosos financeiramente foram sendo substituídos pela visão de união sacra, sem prazer físico ou material. A dimensão carnal era gradativamente alterada para um aspecto idealizado e místico, em uma sociedade cada vez mais hostil à figura feminina comum e em exaltação crescente ao culto da Virgem Maria. É nesse ambiente contraditório que surgem as figuras do trovador, do cavaleiro e sua dama, e "as representações do amor não-satisfeito e impossível [...] na qual amor e morte estão intimamente associados" (ROSENFIELD, 1992, p. 26).

Ainda segundo a autora, é a partir da criação dessas figuras amorosas que começa "um processo extremamente lento de transformação durante o qual nasce nossa sensibilidade moderna, isto é, uma consciência que concebe o amor como realidade complexa, oscilando entre [...] a necessidade fisiológica e a dedicação altruísta” (ROSENFIELD, 1992, p. 21). Tal conceito também é partilhado por Pretto et al (2009), que nos informam que a idealização do amor continua a influenciar a sociedade através das figuras da Boa Esposa/Bom Marido, pertencentes a normas e regras que fazem da relação amorosa um fim em si mesmo. A concepção do "amor incondicional, que tudo suporta, tudo releva, é sacrifício, abdicação e dedicação", concebe-se "na negação da totalidade do ser humano": o homem só existe porque ele ama (PRETTO et al 2009, p. 396).

De acordo com Rougemont (1988), o mito do Amor-paixão é o nosso legado ocidental. Enquanto tema universal da literatura, o amor surge nas primeiras estórias transmitidas oralmente como um sentimento sensual e divino que exaltava a vida e a fertilidade. Como força da natureza, tal amor bravio era desprovido de regras definidas e refletia os costumes sociais 
das tribos bárbaras e povos antigos. Para estas sociedades, a conjunção carnal entre homens, deuses, seres mágicos ou amorfos representava força, poder e dons maravilhosos. A partir do surgimento das religiões monoteístas, tais narrativas ganham um aspecto mais mistificado e desconhecido.

Conforme o aumento do Cristianismo e da força sócio-política da Igreja, a sociedade altera seus costumes, instituindo regras comportamentais, sobretudo, nas relações pessoais, como a sacralidade do casamento e a fidelidade conjugal. Tais mudanças geraram um conflito sócio-amoroso cuja consequência será a criação da noção do "desejo proibido", originando o Amor-paixão, um amor pleno de obstáculos e separações. Para Rougemont (1988), tal conceito, fruto da união do paganismo natural com o místico cristão, originará o Amor Cortês e, posteriormente, a relação entre Amor e Morte.

O autor afirma igualmente que "o mito sagrado do amor cortês do século XII tinha por função social ordenar e purificar as forças anárquicas da paixão" (ROUGEMONT, 1988, p. 199) em resposta aos conflitos da Alma versus Corpo de uma sociedade ainda pagã em muitos costumes, cuja influência celta impulsionava "um amor sensual que afirmava o orgulho de viver” (ROUGEMONT, 1988, p. 39). Ainda para este autor, essa incompatibilidade moral alimentou a visão do adultério sofrido e condenado, enaltecido pelo Romantismo do século XIX e disseminado pela literatura da época. $\mathrm{O}$ autor vai mais além. Segundo ele, por mais modernas que sejam as relações atuais, as "leis" do amor cortês ainda existem atualmente, porém, sob uma ótica difusa. Do ocidente passional criado pela Idade Média até o presente, as pessoas são educadas para o casamento (e seus hábitos) ao mesmo tempo em que vivem imersas no mito do amor-paixão: "a paixão é a experiência suprema que todo homem deve um dia conhecer e somente aqueles que passam por ela, poderão viver a vida em sua plenitude" (ROUGEMONT, 1988, p. 229).

O que resulta dessas representações sobre o amor nos lais investigados?

\section{Espaços e representações das mulheres e o amor na Idade Média: uma análise comparativa}

Após a leitura e a análise dos vinte e três lais que compõem o nosso corpus, identificamos e destacamos a incidência de espaços geográficos externos e internos neles contidos, como também a representação das mulheres pelos autores e os enamoramentos entre os amantes. As narrativas estudadas foram "Desiré", “Tyolet", "Guingamor", "Espinheiro", “Doon", “Tydorel”, “Graelent”, "Melion”, “Nabaret”, “Trote” e "Passarinho”, em Anônimos (2013); 
"Guigemar", "Equitan", "Freixo", "Homem-lobo", "Lanval”, "Dois Amantes", "Yonec", "Rouxinol”, "Milun”, “O infortunado", "Madressilva" e "Eliduc”, escritos por Maria de França (2001).

Os gráficos abaixo ${ }^{8}$ representam o total de $100 \%$ dos espaços específicos onde ocorrem as narrativas. Destes $100 \%$, temos 34,9\% dos lais ambientados tanto na Bretanha Inglesa (ver parte do gráfico em cor azul) quanto na Bretanha Francesa (ver parte do gráfico em cor vermelha). A parte amarela do gráfico indica que os espaços dos lais não são definidos, ou seja, não sabemos se eles se passam em uma Bretanha ou outra.

Quanto à visão do ser amado, a análise dos textos, através das leituras comparadas, suscitam que, na obra de Maria de França, essa visão dá-se em locais ligados ao ambiente doméstico, como pomares, jardins ou dormitórios (representados nos gráficos pela cor roxa como "outros"), uma vez que, para a poetisa, as damas viviam limitadas ao lar, totalizando, assim, 28\% de encontros amorosos ocorridos no pomar (representado no gráfico pela cor verde)

Em oposição, encontram-se os lais mais antigos e livres da influência católica, apresentando $27 \%$ das florestas (ver parte do gráfico em azul) como ponto de encontro entre as damas e seus cavaleiros. É também na floresta que são encontrados os castelos mágicos, os animais encantados ou "inacessíveis" ao homem comum, bem como fontes (apresentadas no gráfico em cor amarela), as clareiras e rios (contemplado no gráfico como "outros" em cor roxa), que exercem uma influência direta no encontro entre os amantes.

\section{Gráfico 1 - PAÍSES}

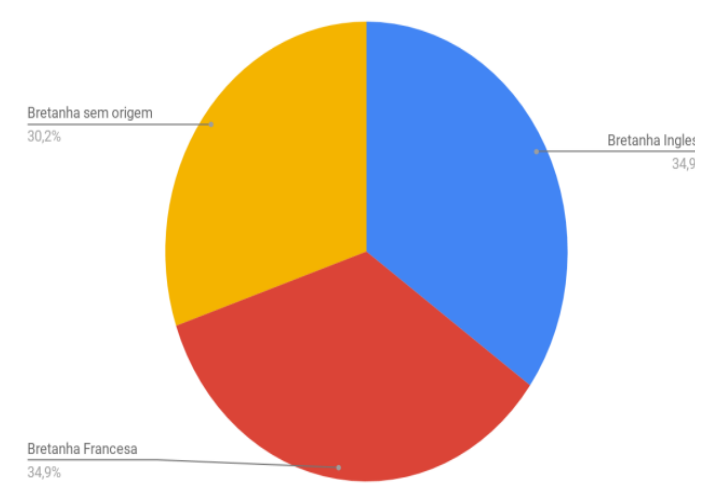

Fonte: Milesa Berset (2019)
Gráfico 2 - LUGARES

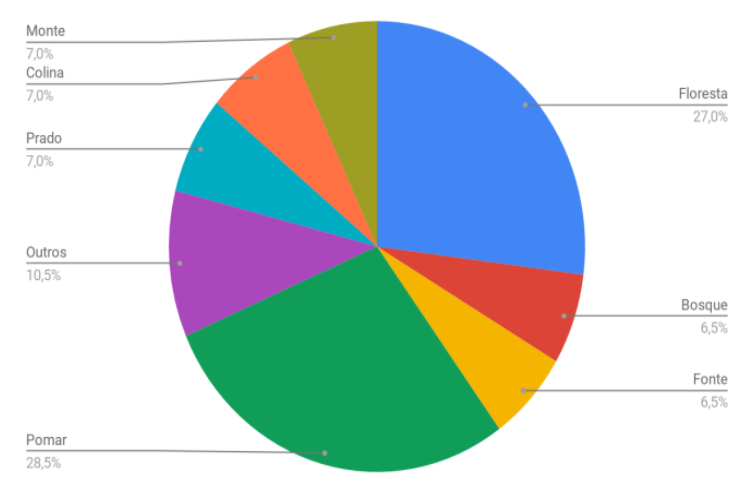

Fonte: Milesa Berset (2019)

\footnotetext{
${ }^{8}$ Os gráficos abaixo foram elaborados pela discente Milena da Costa Berset durante a primeira fase do Projeto de Iniciação Científica PIBIC-CNPq 2019-2020 sob nossa orientação.
} 
Sabemos, através do breve panorama da Idade Média apresentado anteriormente, que as mulheres representam um dos elementos mais importante dos lais. Observamos os espaços dos encontros das mulheres nos gráficos e demonstramos que eles se apresentam de formas distintas. Vale ressaltar que, nos Lais dos Bretões (2013), as mulheres são classificadas como Damas da corte e Damas misteriosas. Em nossa análise, observamos que as mulheres misteriosas não possuem uma origem definida. Contudo, alguns indícios suscitados nas narrativas sugerem que elas pertençam a um mundo outro que não ao do cavaleiro. Em Lais de Maria de França (2001), por exemplo, apenas no lai "Lanval" a poetisa apresenta uma Dama misteriosa representada como uma fada. Nos outros lais, todas as outras personagens femininas pertencem ao mundo terreno, mesmo que vivam aventuras de cunho maravilhoso.

Quais os sentimentos das Damas nobres? O gráfico abaixo demonstra que essas apresentam sentimentos mais intensos, tais como amor, ciúme, ódio e vingança, em relação às outras Damas, denominadas por nós de misteriosas. Estas demonstram sentimentos de altruísmo e amor genuíno. No entanto, apresentam condições de conquista impostas por elas, condições tais que devem ser superadas pelos cavaleiros para que possam merecer o amor delas. Elencamos os adjetivos encontrados nos lais e representados no gráfico abaixo, que retratam o perfil dessas damas. A leitura do gráfico foi feita no sentido horário: Obediente (3,2\%); Cortês (17,9\%); Bela (23,2); Prudente (13,7\%); Muito bela (13,7\%); Gentil (15,8\%); Educada (6,3\%); Refinada (3,2\%) e Orgulhosa $(2,1 \%)$.

\section{Gráfico 3 - PERFIL DAS DAMAS}

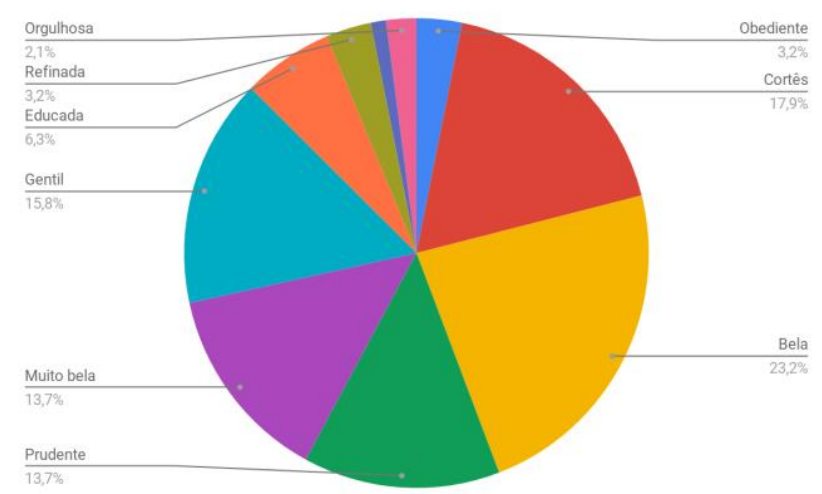

Fonte: Milesa Berset (2019)

Constatamos que, dos doze lais de Maria de França, cinco apresentam damas casadas que se enamoram de outros homens, e são eles: "Guigemar", "Equitan", "Yonec", "Rouxinol" e "Madressilva". Os maridos traídos são descritos como velhos ou ciumentos, onde, apenas no 
lai "Equitan", o nobre tem bom coração. Ressaltamos igualmente que o amor nos Lais de Maria de França (2001) tende para o sofrimento, com a incidência de alguns finais infelizes ou morte dos enamorados. Na obra Lais dos Bretões (2013), ressaltamos que a incidência de final feliz é maior. Contabilizamos um total de seis finais felizes, sendo três no mundo real e três no mundo mágico. O sofrimento da Dama nobre acontece em "Desiré”, "Graelent", "Guingamor" e "Doon", ou seja, em apenas quatro deles.

Nos vinte e três lais analisados, o amor nasce simplesmente assim que se avista o amado ou da simples menção de seus feitos e aventuras. O nascimento do sentimento do amor é apresentado, se pensarmos em termos de percentagem, em $46 \%$ dos lais, indicando o amor cortês masculino, no qual o cavaleiro é quem corteja a dama. Em os Lais dos Bretões (2013), são suscitados outros tipos de enamoramentos, como os cavaleiros que se apaixonam por suas Damas depois de vê-las desnudas ou dormindo. No lai "Doon", por exemplo, a rainha se enamora ao ser vencida em esperteza pelo pretendente, e no lai "Espinheiro", o amor nasce naturalmente do convívio entre os pares.

Emergem de nossas análises dois tipos de amor suscitados na Idade Média literária francesa: um amor cortês mais sensual e selvagem, de forte influência celta e com a presença de seres místicos que compõem os Lais dos Bretões (2013), e o amor cortês apresentado nos lais de Maria de França, cuja interferência cristã concebeu lais mais sociais, com poucos indícios do maravilhoso, no qual a união/desunião entre os amantes é uma forma de redenção espiritual dando margem ao tema da morte, em Lais de Maria de França (2001), visto como algo necessário para que o "amor verdadeiro" possa ser vivenciado sem culpa.

Ressaltamos que, em tais lais, que alcançaram maior notoriedade fora da França, são retratados com maior verossimilhança a sociedade medieval e misógina do século XII, na qual a esposa infiel era merecedora do sofrimento amoroso. Apesar de a autora retratá-las como "mal-casadas", poucas foram as que encontraram um final feliz no amor. Acrescentamos ainda que a violência doméstica também é retratada por Maria de França, enquanto os lais anônimos sugerem um ambiente mais festivo.

Lendo os lais e refletindo à luz das teorias aqui apresentadas, vemos que o amor descrito nos lais é fruto de uma construção social e idealizada do "amor cortês" próprio da época medieval e difundida entre os nobres europeus, principalmente, os franceses e ingleses. $\mathrm{O}$ amor medievo e, consequentemente, cortês, é, possivelmente, a semente do amor romântico que conhecemos hoje em dia, como bem afirmam os teóricos anteriormente citados. 
Certo, os lais analisados apresentam características próprias à sua época e retratam direta ou indiretamente as dicotomias conflituosas da Idade Média. Porém, utilizados pelos trovadores e escritores, eles serviam como instrumentos para a educação moral da nobreza e, posteriormente, da plebe.

Considerando que essas narrativas eram passadas de geração em geração, sua influência repercute até os dias atuais através de idealizações românticas observadas na cultura literária e cinematográfica, teorias defendidas por Pretto et al (2009) e Rougemont (1988). Assim, temos a presença de resquícios do Amor Cortês em nossa sociedade atual, que indica ser resultado da cristalização do "amor ideal" no decorrer dos séculos, através dos sistemas de Objetificação/Ancoragem propostos por D. Jodelet (1984).

\section{Conclusão}

No que tange à pergunta inicial, em que medida as representações sociais do amor da mulher da Idade Média estaria presente na sociedade de hoje em dia?, compreendemos que as representações do amor são construídas com espaços geográficos, em uma Bretanha Francesa, outra Inglesa, e em espaços não definidos. Compreendemos que o perfil das mulheres é apresentado por um campo lexical positivo. As relações amorosas suscitadas nos lais analisados são punições amorosas da época, que, embora estejam tão longe de nossa sociedade atual no ano de 2020, muitos são atuais. Eles estão mais próximos de nós do que pensamos.

Assim, os lais sugerem que a reputação de uma França romântica advém da sedução cultural francesa construída pelos valores do Amor Cortês, o fin 'amor occitano, de rigorosas regras sócio-amorosas praticadas pelos nobres. Como também a evocação da douce france comentada anteriormente neste artigo. Muitas das representações sobre a França e sobre o amor chegam até nós através do discurso de alguns estudantes de Francês Língua Estrangeira, demonstrando que as representações são passadas de geração a geração.

Enfim, os lais sucitam para um leitor atento diversos retratos da sociedade da Idade Média literária francesa. A introdução do gênero em questão pertencente ao medievo pode ser mais próxima do conhecimento prévio do aluno contemporâneo, habituado desde a infância com a leitura, por exemplo, dos contos de fadas. Os lais não estão longe disso. No entanto, nos estudos literários da Literatura da Idade Média Francesa, não seria a ancoragem como um certo enraizamento do pensamento social o que familiariza algo considerado estranho em algo estabelecido na sociedade, gerando ou preconceito ou senso comum e a sua vulgarização? 


\section{Referências}

AMON, É. E BOMATI, Y. Dictionnaire de la littérature française. Paris: Bordas, 2002.

ANÔNIMO. Lais dos Bretões. Tradução de Antônio L. Furtado. PUC-Rio. Rio de Janeiro, 2013.

CERQUIGLINI- TOULET, J. Moyen Âge (XII ${ }^{\mathrm{e}}-\mathrm{XV}^{\mathrm{e}}$ siècle). In : (Org.) Cerquiglini- Toulet, J. et al. La Littérature française : dynamique \& histoire I. Paris : folio essais Inédit, p. 25204, 2007.

FRANCE, M. de. Lais de Maria de França. Tradução de Antônio L. Furtado. Editora Vozes. Petrópolis, 2001.

JODELET, D. Representação social: fenômeno, conceito e teoria. In: Psicologia Social (MOSCOVICI, S.). Paris: PUF, 1984, p. 357-378.

PRETTO, Z. et al. Um olhar sobre o amor no ocidente. Psicologia em Estudo. Maringá, V.14, $\mathrm{N}^{\mathrm{o}}$ 2, abr/jun, 2009, p. 995-403.

ROSENFIELD, K.H. Figuras do amor medieval. In: O amor na literatura (SCHULER, D.). Editora UFRGS. Porto Alegre, 1992.

ROUGEMONT, D. O Amor e o Ocidente. Editora Guanabara. Rio de Janeiro, 1988.

Recebido em: 18/08/2020

Aceito para publicação em: 23/11/2020 